\title{
Glomerular filtration rate and prevalence of chronic kidney disease in Wilms' tumour survivors
}

\author{
Joanna Stefanowicz • Mateusz Kosiak • \\ Grzegorz Romanowicz • Radosław Owczuk • \\ Elżbieta Adamkiewicz-Drożyńska • Anna Balcerska
}

Received: 7 August 2010 /Revised: 18 December 2010 / Accepted: 22 December 2010 /Published online: 29 January 2011

(C) The Author(s) 2011. This article is published with open access at Springerlink.com

\begin{abstract}
Glomerular filtration rate (GFR) was evaluated in 32 Wilms' tumour survivors (WTs) in a cross-sectional study using 99 Tc-diethylene triamine pentaacetic acid (99 Tc-DTPA) clearance, the Schwartz formula, the new Schwartz equation for chronic kidney disease (CKD), cystatin $\mathrm{C}$ serum concentration and the Filler formula. Kidney damage was established by beta-2-microglobulin (B-2-M) and albumin urine excretion, urine sediment and ultrasound examination. Blood pressure was measured. No differences were found between the mean GFR in $99 \mathrm{Tc}$ DTPA and the new Schwartz equation for CKD $(91.8 \pm 11.3$ vs. $94.3 \pm 10.2 \mathrm{ml} / \mathrm{min} / 1.73 \mathrm{~m}^{2}[p=0.55]$ respectively). No differences were observed between estimated glomerular filtration rate (eGFR) using the Schwartz formula and the Filler formula either $(122.3 \pm 19.9$ vs. $129.8 \pm 23.9 \mathrm{ml} / \mathrm{min} /$ $1.73 \mathrm{~m}^{2}[p=0.28]$ respectively). Increased urine albumin and B-2-M excretion, which are signs of kidney damage, were
\end{abstract}

J. Stefanowicz $(\bowtie) \cdot$ E. Adamkiewicz-Drożyńska $\cdot$ A. Balcerska Department of Paediatrics, Haematology, Oncology,

Endocrinology, Medical University of Gdansk,

7 Debinki Street,

80-952 Gdansk, Poland

e-mail: jstefanowicz@gumed.edu.pl

M. Kosiak

Department of Family Medicine, Medical University of Gdansk, Gdansk, Poland

G. Romanowicz

Department of Nuclear Medicine, Medical University of Gdansk, Gdansk, Poland

R. Owczuk

Department of Anaesthesiology and Intensive Therapy,

Medical University of Gdansk,

Gdansk, Poland found in $7(22 \%)$ and $3(9.4 \%)$ WTs respectively. Ultrasound signs of kidney damage were found in 14 patients $(43 \%)$. Five patients $(15.6 \%)$ had more than one sign of kidney damage. Eighteen individuals (56.25\%) had CKD stage I (10 with signs of kidney damage; 8 without). Fourteen individuals (43.75\%) had CKD stage II ( 6 with signs of kidney damage; 8 without). The new Schwartz equation for CKD better estimated GFR in comparison to the Schwartz formula and the Filler formula. Furthermore, the WT survivors had signs of kidney damage despite the fact that GFR was not decreased below $90 \mathrm{ml} / \mathrm{min} / 1.73 \mathrm{~m}^{2}$ with 99 Tc- DTPA.

Keywords 99 Tc-DTPA - eGFR formulas · Cystatin C . CKD · Wilms' tumour survivors

\section{Introduction}

Wilms' tumour is the most frequently diagnosed tumour in the kidneys of children [1]. It represents approximately $7 \%$ of all malignancy in children [2]. Currently, the treatment of Wilms' tumour is successful in approximately $90 \%$ of cases, and the treatment utilises a combination of induction chemotherapy, nephrectomy, postoperative chemotherapy and in some cases radiation therapy [2,3]. The quality of life of the patient depends on the potential long-term side effects of the treatment, such as the impairment of function of a single kidney.

All treatments may have a potential long-term influence on the function of solitary kidneys in Wilms' tumour survivors. According to Daw et al., the most severe reduction in glomerular filtration rate (GFR; a reduction of 32\%), measured by 99 Tc-DTPA clearance occurred after nephrectomy [4]. Chemotherapy consists of 
nephrotoxic agents, such as carboplatin and ifosfamide, and is administered in the advanced stages and in high-risk Wilms' tumours. This treatment may also cause renal function to deteriorate $[5,6]$. Two courses of ifosfamide, carboplatin and etoposide (ICE) reduced GFR by $7 \%$ and GFR did not decline after another course [4]. Chemotherapeutic agents, such as vincristine and actinomycin, are frequently used in the treatment of nephroblastomas and do not seem to have nephrotoxic effect. Finally, radiotherapy has been shown to have an adverse effect on kidney function. De Graff et al. observed a lower value of GFR measured by 125 I-iothalamate clearance in Wilms' tumour survivors who underwent radiation of their abdomen compared with patients who did not undergo radiation [7].

Decreasing the number of nephrons causes a compensatory increase in the filtration of the remaining nephrons to maintain excretory demands. However, hyperfiltration may lead to progressive glomerular sclerosis and a further reduction in nephrons [8,9]. Thus, Wilms' tumour survivors are at risk of impairment of renal function in the years following the treatment. This possible complication makes early detection of the deterioration of renal function an important need for Wilms' tumour patients.

The monitoring of GFR in the outpatient department is based on equations that may have a bias compared with the current gold standard, inulin clearance. The National Kidney Foundation (NKF) recommends the Schwartz formula to estimate GFR in children [10]. Cystatin C is a low molecular weight protein that is produced in a constant amount by all nuclear cells and is eliminated from circulation by glomerular filtration [11, 12]. Although the NFK does not recommend this, reports claim that cystatin $\mathrm{C}$ can be used to assess glomerular filtration in children [13]. In 2003, Filler showed that estimating the GFR using a formula that reflects the relation between the cystatin $\mathrm{C}$ serum concentration and eGFR is much more accurate to assess glomerular filtration than the Schwartz formula [14]. In addition, Schwartz recently published a new equation to estimate GFR in children with chronic kidney disease (CKD). The new formula is based on the serum concentration of creatinine, cystatin $\mathrm{C}$ and ureic nitrogen [15].

The first aim of the current study is to compare the Schwarz formula, cystatin $\mathrm{C}$ serum concentration, the Filler formula and the new Schwarz equation for children with CKD with 99 Tc-DTPA clearance in Wilms' tumour survivors.

The second aim is to assess the prevalence of CKD in Wilms' tumour survivors and use the NKF guidelines to detect early kidney damage in individuals who do not have a decreased GFR, but may be at risk of declining GFR [16].

\section{Patients and methods}

\section{Patients}

Thirty-two Wilms' tumour survivors followed as outpatients at the Medical University of Gdansk were enrolled in this cross-sectional study. All participants had undergone unilateral nephrectomy and had been treated according to the chemotherapy protocols SIOP 9, SIOP 1992, SIOP 2001 between the years 1987 and 2008 [17].

All patients came for an interview where they were asked questions regarding past medical history of renal disease and urinary symptoms. Blood pressure was measured and the participants donated blood for the measurement of: serum creatinine, blood urea nitrogen and cystatin $\mathrm{C}$; urine for microscopy and the determination of albumin, creatinine and beta2 microglobulin concentrations. All patients underwent renal ultrasound imaging and had their GFR measured with a 99 DTPA renal isotope study.

\section{Methods}

\section{Laboratory tests: assessment of GFR}

99 Tc-DTPA clearance was defined as the serum activity of 99 Tc-DTPA at 1 and $3 \mathrm{~h}$ following the injection of 99 TcDTPA. Results were calculated using a constant body surface area of $1.73 \mathrm{~m}^{2}$.

The Schwartz formula was defined as follows: eGFR in $\mathrm{ml} / \mathrm{min} / 1.73 \mathrm{~m}^{2}=\mathrm{k} \times$ height of child in $\mathrm{cm} / \mathrm{serum}$ creatinine concentration in $\mathrm{mg} / \mathrm{dl}$; where the constant $\mathrm{k}$ was defined using published literature values: $\mathrm{k}=0.55$ for children aged $2-12$ or adolescent females and $k=0.7$ for adolescent males [18].

The new Schwartz equation for children with CKD was defined as follows: eGFR $=39.2 \times$ (height of child in $\mathrm{m} /$ serum creatinine concentration in $\mathrm{mg} / \mathrm{dl})^{0.516} \times(1.8 /$ cystatin $\mathrm{C}$ serum concentration $)^{0.294} \times(30 / \mathrm{BUN})^{0.169} \times$ $\left(1.099^{\text {male }} / 1^{\text {female }}\right) \times(\text { height of child in } \mathrm{m} / 1.4)^{0.188}$ ] [15]

Additionally, serum concentrations of cystatin $\mathrm{C}$ were evaluated and eGFR was presented according to the Filler formula: $\log \mathrm{GFR}=1, .962+[1.123 \times \log (1 /$ cystatin C) [14]

Serum cystatin $C$ concentration was assessed using the nephelometric PENIA method (Dade Behring, Marburg, Germany). Serum creatinine concentrations were assessed using the colorimetric-modified Jaffe method $(\mathrm{mg} / \mathrm{dl})$. Blood-ureic nitrogen concentration was assessed using the enzymatic-modified Talke and Schubert method (mg/dl).

Albumin urine concentrations were assessed using the immunological method, Multigent, from Abbott Laboratories (Wiesbaden, Germany). Increased excretion of albumin with the urine was evaluated as a concentration 
over $20 \mathrm{mg} / \mathrm{L}$ and urine albumin to creatinine ratio (ACR) over $30 \mathrm{mg} / \mathrm{g}$ [19]. B-2-M urine concentration was evaluated with Quantia $\beta 2$-microglobulin (BIOKIT, Barcelona, Spain) as both a concentration and a urine B-2-M to creatinine ratio (BCR). The cut-off value for the increased excretion of $\mathrm{B}-2-\mathrm{M}$ with urine was over $0.32 \mathrm{mg} / \mathrm{dl}$ and $0.04 \mathrm{~g} / \mathrm{mol}$ for BCR [20]. All individuals enrolled in the study also had a urine test evaluated and urine sediment analysed. At the time of evaluation, none of the children had a urinary tract infection confirmed by urine samples and an assessment of their blood CRP levels.

Value of GFR assessed as clearance of 99 Tc-DTPA, ACR, BCR, urine sediment analysis and ultrasound examination were used for classification of patients into stages of CKD.

\section{Ultrasound examination}

In all individuals enrolled in the study, a solitary kidney was assessed for ultrasound signs of kidney damage as defined by the NKF: nephrocalcinosis, cysts, hydronephrosis, stones, change in the size of the kidney and scars [21]. In the present study, hyperechoic rings around kidney pyramids were also assessed as a sign of kidney damage [22]. Patients were examined in the prone position. The acoustic windows used in the ultrasound were the lumbar muscles. Examination conditions were the same for every patient. All patients were asked not to drink any fluids $1 \mathrm{~h}$ before the examination. All ultrasound examinations were performed by the same sonographer (M.K.), using the same equipment (GE Logic 500; GE Medical Systems, Waukesha, WI, USA).

\section{Blood pressure}

Blood pressure (BP) was measured in every child in the study by an auscultatory method that used a standard clinical sphygmomanometer (Maxi Stabil 3; Speidel and Keller, Jungingen, Germany) and a stethoscope. This method followed the guidelines established by The Fourth Report on the Diagnosis, Evaluation, and Treatment of High Blood Pressure in Children and Adolescents [23]. Each patient had their blood pressure measured three times. Mean values of systolic and diastolic pressure were determined for every Wilms' tumour survivor. The results were then compared with reference values matched accordingly to gender, age and height.

\section{Statistical analysis}

Statistical analysis was performed using the Statistica 8.0 PL software (Polish version; StatSoft, Tulsa, OK, USA). A normal distribution of the data was verified using the $\mathrm{W}$ Shapiro-Wilk test. Homoscedasticity was verified using the
Levene test. Inter-group comparisons were performed using the Student's $t$ test for independent data. A correlation analysis was performed using Pearson's or Spearman's methods, depending on the character and distribution of the correlated data. The level of significance was set to $p<0.05$.

Ethics committee

This study was approved by the Independent Bioethical Committee of Scientific Researchers at the Medical University of Gdansk. Written informed consent was obtained from the legal guardians of the children.

\section{Results}

Patients' characteristics

Thirty-two patients were enrolled in the current study: 13 girls and 19 boys (Table 1$)$. Seven patients $(21.9 \%)$ were treated with nephrotoxic agents, such as carboplatin and ifosfamide. The characteristics of the 7 individuals who received potentially nephrotoxic agents is presented in Table 2. Two of those 7 individuals also received irradiation to the remnant kidney (Table 2). Twelve individuals (37.5\%) underwent radiation therapy. In 3 cases the remnant kidney underwent irradiation. Nephrotoxic agents were administered in the treatment of 2 of those 3 individuals (Table 2; patients 6 and 7). One person underwent radiation of the solitary kidney, but did not receive potentially nephrotoxic agents (Table 2; patient 8)

\section{Glomerular filtration rate}

The mean values and standard deviations of glomerular filtration rates assessed with the methods described are shown in Table 3. No statistical difference was found between the mean eGFR assessed with the Schwartz formula and that assessed with the Filler formula $(p=0.26)$. There was a

Table 1 Characteristics of the patients enrolled in the study

\begin{tabular}{lllll}
\hline & Mean & $\begin{array}{c}\text { Standard } \\
\text { deviation }\end{array}$ & Median & Range \\
\hline Age (years) & 13 & 5.4 & 12.2 & $3.6-24.3$ \\
$\begin{array}{l}\text { Time of } \\
\text { follow-up (years) }\end{array}$ & 9.3 & 5.4 & 7.75 & $0.3-20.6$ \\
$\begin{array}{l}\text { Weight (kg) } \\
\text { Height (cm) }\end{array}$ & 43.9 & 16.8 & 42.8 & $21.7-77.4$ \\
$\begin{array}{c}\text { BMI (kg/m }{ }^{2} \text { ] } \\
\text { Age at time of }\end{array}$ & 18.5 & 20.7 & 154 & $110-184.5$ \\
diagnosis (years) & 8.52 & 5.7 & 2.9 & $0.08-11.4$ \\
\hline
\end{tabular}

BMI, body mass index 


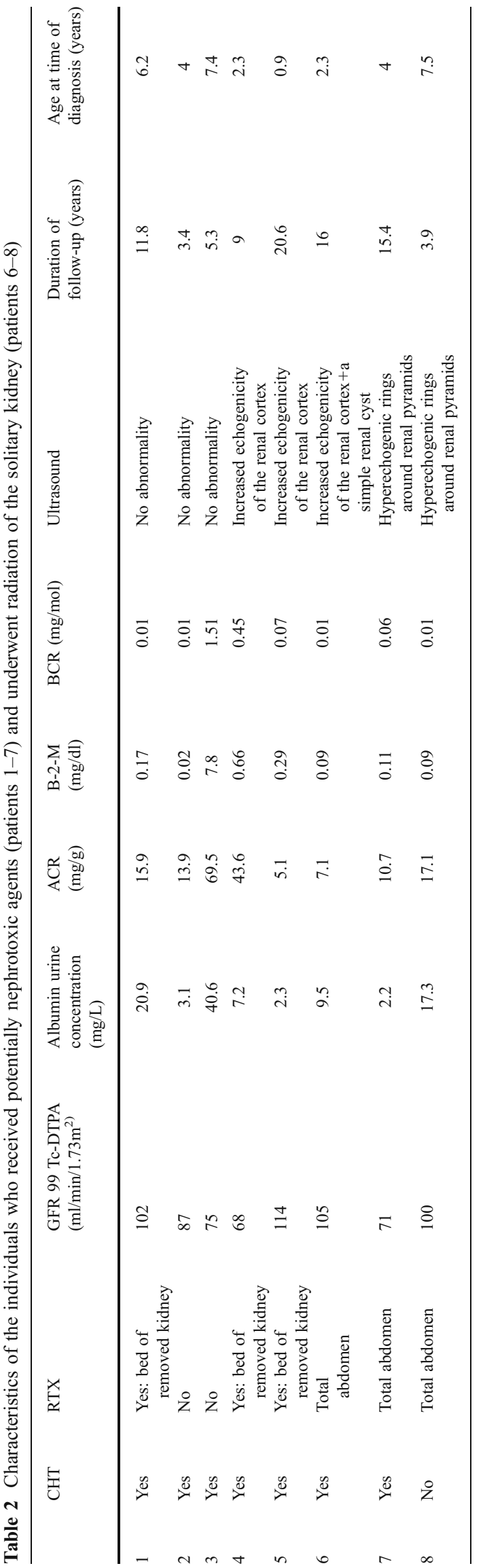

Table 3 Mean values of GFR and standard deviation (SD) assessed with different methods and the mean value and the SD of cystatin $\mathrm{C}$ serum concentration

\begin{tabular}{lll}
\hline & Mean GFR $\left(\mathrm{ml} / \mathrm{min} / 1.73 \mathrm{~m}^{2}\right)$ & SD \\
\hline GFR 99 Tc-DTPA & 94.28 & 10.24 \\
eGFR Schwartz & 122.26 & 19.92 \\
eGFR new Schwartz & 94.26 & 10.22 \\
$\quad$ equation for children & & \\
$\quad$ with CKD & 0.76 & 0.12 \\
Cystatin C & 129.83 & 23.89 \\
eGFR Filler & &
\end{tabular}

GFR, glomerular filtration rate; eGFR, estimated glomerular filtration rate; 99 Tc-DTPA, 99 Tc-diethylene triamine pentaacetic acid; CKD, chronic kidney disease

statistical difference between the GFR assessed with 99 Tc-DTPA clearance and first, the eGFR assessed with the Schwartz formula $(p<0.0001)$, second, the eGFR assessed with the Filler formula $(p<0.0001)$. There was a statistical difference between the new eGFR equation for children with CKD and first, the Schwartz formula $(p<0.0001)$, second, the Filler formula $(p<0.0001)$. There was no statistical difference between the GFR assessed with 99 Tc-DTPA clearance and the new eGFR equation for children with CKD $(p=0.55)$. The correlation rate between the GFR with 99 Tc-DTPA clearance and the eGFR assessed with first, the Schwartz formula, was $0.33(p<0.05)$, second, the Filler formula, was $0.44(p<0.05)$, third, the new equation for children with CKD was $0.33(p<0.05)$ and fourth, the serum cystatin $\mathrm{C}$ concentration, was $0.51(p<0.05)$.

According to the method of assessment of eGFR, the prevalence of patients with decreased GFR below $90 \mathrm{ml} / \mathrm{min} /$ $1.73 \mathrm{~m}^{2}$ differed (Table 4). Four patients enrolled in the study had serum concentrations of cystatin C over $0.95 \mathrm{mg} / \mathrm{dl}$. None of these patients had a GFR decrease below $60 \mathrm{ml} / \mathrm{min} /$ $1.73 \mathrm{~m}^{2}$.

There were no statistical differences in the mean values of GFR for 99 Tc-DTPA patients who received nephrotoxic treatment $\left(n=7 ; 92.68 \pm 8.7 \mathrm{ml} / \mathrm{min} / 1.73 \mathrm{~m}^{2}\right)$ and those who did not receive the treatment $(n=25 ; 88.86 \pm 18.3 \mathrm{ml} / \mathrm{min} /$ $1.73 \mathrm{~m}^{2} ; p=0.43$ ).

Table 4 Number of patients with a decreased GFR

Number of patients with decreased GFR $\left(<90 \mathrm{ml} / \mathrm{min} / 1.73 \mathrm{~m}^{2}\right)$;

GFR 99Tc-DTPA

$14(43.8 \%)$

eGFR Schwartz

$1(3.1 \%)$

eGFR new Schwartz equation $11(34.4 \%)$

for children with CKD

eGFR Filler

CKD chronic kidney disease 
Signs of kidney damage

Increased excretion of albumin (albumin to creatinine ratio $>30 \mathrm{mg} / \mathrm{g}$ ) was observed in 7 out of 32 patients (22\%); an increased urine concentration $(>20 \mathrm{mg} / \mathrm{L})$ was observed in 6 patients (19\%). Excretion of B-2-M with urine was elevated to over $0.32 \mathrm{mg} / \mathrm{dl}$ in 3 patients and to over $0.04 \mathrm{~g} / \mathrm{mol}$ in 4 patients. There were no abnormalities in the urine sediment.

Five Wilms' tumour survivors had more than one sign of kidney damage: 2 patients had increased excretion of albumin and B-2-M; 2 patients had increased excretion of albumin and signs of kidney damage in the ultrasound examination; and 1 patient had increased excretion of B-2-M and signs of kidney damage in ultrasound examination.

Renal ultrasound findings

The signs of kidney damage in the ultrasound examination were observed in 14 out of 32 patients (43\%; Table 5).

Prevalence of CKD in Wilms' tumour survivors

Eighteen patients were classified as stage I of CKD: solitary kidney with (10 patients) or without (8 patients) signs of kidney damage with a value of GFR of over $90 \mathrm{ml} / \mathrm{min} /$ $1.73 \mathrm{~m}^{2}$. Fourteen patients were classified as having stage II CKD. Among those, 6 patients had markers of kidney damage (Table 6).

\section{Blood pressure}

Arterial hypertension, based on the mean values of systolic and diastolic blood pressures from three independent measurements, over the 95th centile was observed in 2 individuals (6.25\%). Two people (6.25\%) enrolled in the study had diastolic blood pressure over the 95th centile. One of them had systolic blood pressure over the 90th centile. Mean systolic and diastolic blood pressures over the 90th centile were observed in 2 Wilms' tumour survivors $(6.25 \%)$. One person had systolic blood pressure over the

Table 5 Prevalence of signs of kidney damage in ultrasound examination

\begin{tabular}{ll}
\hline $\begin{array}{l}\text { Sign of kidney damage in } \\
\text { ultrasound examination }\end{array}$ & Number of patients \\
\hline Hyperechoic rings around renal pyramids & 12 \\
Renal scars & 3 \\
Echogenicity of renal cortex & 5 \\
Urolithiasis & 0 \\
Cysts & 1 \\
\hline
\end{tabular}

Table 6 Prevalence of CKD in Wilms' tumour survivors

\begin{tabular}{lll}
\hline CKD stage I & $\begin{array}{l}\text { GFR }>90 \mathrm{ml} / \mathrm{min} / 1.73 \mathrm{~m}^{2} \\
\text { no signs of kidney damage } \\
\text { GFR }>90 \mathrm{ml} / \mathrm{min} / 1.73 \mathrm{~m}^{2}+ \\
\text { signs of } \mathrm{kidney} \mathrm{damage} \\
\text { patients }\end{array}$ \\
$\begin{array}{c}\text { GFR } 60-89 \mathrm{ml} / \mathrm{min} / 1.73 \mathrm{~m}^{2} \\
\text { no signs of } \mathrm{kidney} \text { damage } \\
\text { GFR } 60-89 \mathrm{ml} / \mathrm{min} / 1.73 \mathrm{~m}^{2}+ \\
\text { signs of kidney damage }\end{array}$ & 8 \\
\hline
\end{tabular}

90th centile. None of the individuals enrolled to the study had been administered antihypertensive drugs.

\section{Discussion}

The current study compared the values of GFR measured with 99 Tc-DTPA clearance, a reference method, with eGFR evaluated using other methods: the Schwartz formula, which is the formula recommended by the NKF; the new Schwartz equation, which is used for children with $\mathrm{CKD}$; serum cystatin $\mathrm{C}$ concentration, which is a low molecular protein that may become an alternative for creatinine serum concentration used to detect early glomerular impairment in children; and the Filler formula, which is a mathematical formula based on cystatin $\mathrm{C}$.

There was no statistical difference between GFR 99 TcDTPA and the new eGFR equation for children with CKD $(p=0.55)$ in the present study. No difference was observed in the mean values of GFR for 99 Tc-DTPA of patients who did and did not receive nephrotoxic treatment $(p=0.43)$. Among all individuals enrolled in the study, 7 (22\%) had increased albumin urine excretion; $3(9.3 \%)$ presented increased B-2-M urine excretion and 14 (43\%) had signs of kidney damage on ultrasound examination. The prevalence of CKD in the study was as follows: 18 patients were classified as CKD stage I and 14 as CKD stage II.

The values of 99 Tc-DTPA clearance obtained in this study were similar to values previously published in the literature on Wilms' tumour survivors. In a study by Levitt et al., 19\% of individuals after treatment for nephroblastoma had decreased GFR (below $80 \mathrm{ml} / \mathrm{min} / 1.73 \mathrm{~m}^{2}$ ) measured as clearance of 51-chromium diamine tetraacetic acid (51 Cr-EDTA) [24]. Srinivas et al. did not observe any decreased GFR in Wilms' tumour survivors using the 99 Tc-DTPA clearance [25]. The GFR of single kidneys in individuals after treatment for Wilms' tumour was measured with 125 I-iothalamate clearance by De Graaf et al. The authors noticed that GFR in children who did not receive radiation therapy on the single kidney had a mean 
GFR of $94.6 \%$ of the normal rate and those who received radiation therapy to their solitary kidney had a mean GFR of $72.7 \%$ of the normal rate [7]. Schell et al. evaluated GFR in Wilms' tumour survivors using inulin clearance. The mean values of GFR were $85 \mathrm{ml} / \mathrm{min} / 1.73 \mathrm{~m}^{2}$ [26]. According to Chevallier et al., the mean inulin clearance in Wilms' tumour survivors was $93 \mathrm{ml} / \mathrm{min} / 1.73 \mathrm{~m}^{2}$ [27].

In the current study, the eGFR estimated with the Schwartz formula was significantly higher than the GFR measured with 99 Tc-DTPA. The fact that the Schwartz formula overestimates eGFR by approximately $10 \mathrm{ml} / \mathrm{min} / 1.73 \mathrm{~m}^{2}$ is a well-known phenomenon [28]. Seikaly et al. reported that this overestimation can reach even $20 \mathrm{ml} / \mathrm{min} / 1.73 \mathrm{~m}^{2}$ in individuals with decreased eGFR [29]. The difference between inulin clearance and creatinine clearance in Wilms' tumour survivors was presented by Donckerwolcke and Coppes: $82.3 \mathrm{ml} / \mathrm{min} / 1.73 \mathrm{~m}^{2}$ and $176.2 \mathrm{ml} / \mathrm{min} / 1.73 \mathrm{~m}^{2}$ respectively [30]. Thus, detection of individuals with eGFR between 90 and $60 \mathrm{ml} / \mathrm{min} / 1.73 \mathrm{~m}^{2}$ with the Schwartz formula is difficult. Mattman et al. underlined the need for a derivation of the Schwarz formulas in a local laboratory setting to avoid bias [31].

A marker for CDK, which may be more sensitive to the detection of early renal impairment, is cystatin $\mathrm{C}$, although it is not recommended by the NKF to evaluate renal function [28]. According to Kazama et al., a cystatin C serum concentration over $0.98 \mathrm{mg} / \mathrm{dl}$ has a sensitivity of $88.5 \%$ and a specificity of $95.2 \%$ for detecting GFR below $80 \mathrm{ml} / \mathrm{min} /$ $1.73 \mathrm{~m}^{2}$ [32]. Our study presented a higher correlation rate between 99 Tc-DTPA and serum concentration of cystatin $\mathrm{C}$ than between 99Tc-DTPA and eGFR Schwartz formula: -0.51 vs. 0.33 respectively. The value of cystatin $C$ serum concentration that should act as the cut-off value to avoid impairment of the filtration rate is still unknown. Fischbach et al. proposed a value of $0.95 \mathrm{mg} / \mathrm{dl}$ as a cut-off value and this is the highest value published in the literature [13]. According to Stefanowicz et al., $42 \%$ of individuals after treatment of Wilms' tumour had a serum concentration of cystatin C that was elevated to over $0.95 \mathrm{mg} / \mathrm{dl}$ [33].

Filler and Lapage proposed a mathematical formula that expresses the relation between cystatin $\mathrm{C}$ serum concentrations and eGFR [14]. Authors reported that agreement between 99 Tc-DTPA and eGFR by the Schwartz formula showed a bias of $10.8 \%$. Agreement between 99 Tc-DTPA and the Filler formula presents bias of only $0.3 \%[14,18]$. In our study, we did not observe a difference in mean values of eGFR between the Schwartz and Filler formulas, and we observed a statistical difference between eGFR by the Filler formula and 99 Tc-DTPA clearance. The correlation between the two methods was 0.44 . Our study reported that the Filler formula is not superior over the Schwartz formula in the detection of early renal impairment in Wilms' tumour survivors. In the current study, cystatin $\mathrm{C}$ serum concentration $(r=0.51)$ correlated better with 99 Tc-DTPA than with eGFR assessed with the Filler formula $(r=0.44)$. Also, cystatin $\mathrm{C}$ serum concentration over $0.95 \mathrm{mg} / \mathrm{dl}$ determines decreased GFR in 99Tc-DTPA in more individuals than eGFR with the Filler formula.

Recently, Schwartz et al. published a new equation to estimate GFR in children. The formula is based on the serum concentration of creatinine, BUN and cystatin $\mathrm{C}$ [15]. The equation was established from 349 children with CKD and a mean GFR of $41.2 \mathrm{ml} / \mathrm{min} / 1.73 \mathrm{~m}^{2}$ measured as iohexol plasma disappearance. The formula yielded an eGFR of $87.7 \%$ within an iohexol GFR of $30 \%$ [15]. In the current study, the new equation is found to have a better detection of CKD in Wilms' tumour survivors than both the Schwarz and the Filler formulas. This is despite the fact that individuals enrolled in the study had higher values of GFR than those in the study by Filler and Lepage [14].

Currently, in light of the definition of chronic kidney disease for individuals with a risk of deterioration of kidney function, it is essential not only to objectively assess GFR, but also to establish of the presence of markers of kidney damage. Markers of kidney damage are structural or functional abnormalities that may lead to decreased GFR [34]. The NKF recommends evaluation of proteinuria as a marker of kidney damage in children and albuminuria in adults [35]. In adults, kidney damage is frequently an outcome of glomerular diseases that are due to hypertension or diabetes. In children, kidney damage is an outcome of congenital tubular abnormalities, which is why proteinuria is more sensitive [35]. The deterioration of kidney function in Wilms' tumour survivors is due to glomerular damage caused by hyperfiltration [8, 9]. Thus, individuals enrolled in the current study had their albumin to creatinine ratio assessed. The value of the ratio was increased in $22 \%$ of the individuals enrolled in the current study. The increased excretion of albumin with urine in Wilms' tumour survivors has been assessed in previously published studies. In studies by Di Tullio et al., Cioce et al., Levitt et al. and Srinivas et al., the prevalence of increased albumin excretion with urine was $32 \%, 37 \%, 9 \%$ and $84 \%$ respectively [24, 25, 36, 37].

Other laboratory markers of kidney damage included abnormal urine sediment. There was no abnormality in the urine sediment in the group analysed. Increased excretion of B-2-M was noticed in three individuals. All of them presented other signs of kidney damage, so the presence of B-2-M did not influence the prevalence of CKD in the study's population. Individuals with increased excretion of B-2-M were observed in a similar manner to people who obtained nephrotoxic treatment.

Structural abnormalities in kidneys can be detected in imaging studies. The NKF recommends using ultrasound, intravenous pyelography, computed tomography, magnetic 
resonance imaging, or nuclear scans. Ultrasound is an imaging test that is the most frequently performed in Wilms' tumour survivors. In our study, we exceeded the ultrasound signs of kidney disease compared with that presented by the NKF [21]. Additionally, we evaluated the presence of hyperechoic rings around renal pyramids, which is an outcome of tubular dysfunctions [22, 38]. According to our knowledge in previously presented studies, structural abnormalities in ultrasound examination were not considered.

Blood pressure is not an integral part of the definition of $\mathrm{CKD}$, although it may act as a clinical marker of kidney diseases [10]. Presence of hypertension in individuals with CKD may increase the risk of cardiovascular complications. Arterial hypertension (systolic and diastolic blood pressure above the 95th centile) was diagnosed in two individuals (6.25\%). Another two individuals (6.25\%) had systolic and diastolic blood pressure above the 90th centile, but below the 95th centile. Prevalence of hypertension in the present study is lower than in previously published studies-11-29\% of the total cases [23, 39].

The prevalence of CKD in Wilms' tumour survivors has not yet been analysed. All patients who underwent treatment for Wilms' tumour can be considered to have CKD, since they lack a kidney. In the current study, 18 (56.25\%) individuals had stage I CKD: 10 of them had signs of kidney damage; in 8 cases those signs were not observed. Fourteen Wilms' tumour survivors $(43.75 \%)$ were classified as having stage II CKD. Six of them had signs of kidney damage. In 8 cases those signs were not observed (Table 6). The main therapeutic goal in an individual with stage I CKD is to treat the comorbid conditions and reduce the risk of cardiovascular diseases. In stage II of CKD, the goal is to estimate the progression of CKD.

To appropriately test for $\mathrm{CKD}$, prospective follow-up must be planned to assess the risk of deterioration of function of the single kidney in Wilms' tumour survivors with and without markers of kidney damage.

To conclude the study we claim that the evaluation of a single kidney in Wilms' tumour survivors should consist of the assessment of eGFR, albumin and B-2-M urine excretion, urine sediment analysis and ultrasound examination. A new equation (the new Schwartz formula) for the estimation of eGFR in children with CKD was found to better predict eGFR more accurately than the Schwartz formula and the Filler formula in comparison to $99 \mathrm{Tc}-$ DTPA clearance. Thus, the new Schwartz formula ought to be considered the method of GFR estimation to be used in everyday practice.

It needs to be underlined that although GFR did not decrease below $90 \mathrm{ml} / \mathrm{min} / 1.73 \mathrm{~m}^{2}$ with 99 Tc-DTPA, Wilms' tumour survivors still displayed signs of kidney damage in laboratory and ultrasound examinations. It is essential to additionally evaluate the presence of albumin, B-2-M urine excretion and ultrasound signs of kidney damage that may indicate early renal impairment.

Open Access This article is distributed under the terms of the Creative Commons Attribution Noncommercial License which permits any noncommercial use, distribution, and reproduction in any medium, provided the original author(s) and source are credited.

\section{References}

1. Gupta Devendra K, Sharma S, Agarwala S, Carachi R (2005) Saga of Wilms' tumor: lessons learnt from the past. J Indian Assoc Pediatr Surg 10(4):217-228

2. Lisauer T, Clayden G (2001) Illustrated Textbook of Paediatrics, 2nd edn. Mosby, London, pp 285-296

3. Tournade MF, Com-Nougué C, de Kraker J, Ludwig R, Rey A, Burgaers MB, Sandstedt B, Godzinski J, Carli M, Potter R, Zucker JM (2001) Optimal duration of preoperative therapy in unilateral and nonmetastatic Wilms tumor in children older than 6 months: results of the ninth International Society of Pediatric Oncology Wilms Tumor Trial and Study. J Clin Oncol 19:488-500

4. Daw NC, Gregornik D, Rodman J, Marina N, Wu J, Kun EL, Jenkins JJ, McPherson V, Wilimas J, Jones DP (2009) Renal function after ifosfamide, carboplatin and etoposide (ICE) chemotherapy, nephrectomy and radiotherapy in children with Wilms tumor. Eur J Cancer 45:99-106

5. Sleijfer DT, Smit EF, Meijer S, Mulder NH, Postmus PE (1989) Acute and cumulative effects of carboplatin on renal function. $\mathrm{Br}$ J Cancer 60:116-120

6. Goren MP, Pratt CB, Viar MJ (1989) Tubular nephrotoxicity during long term ifosfamide and Mesna therapy. Cancer Chemother Pharmacol 25:70-72

7. De Graff SSN, van Gent H, Reitsma-Bierenes WCC, van Luyk WHJ, Dolsma WV, Postma A (1996) Renal function after unilateral nephrectomy for Wilms tumor: the influence of radiation therapy. Eur J Cancer 32:465-469

8. Thorner P, Arbus G, Celermajer D, Baumal R (1984) Focal segmental glomerulosclerosis and progressive renal failure associated with a unilateral kidney. Pediatrics 73:806-810

9. Zucchelli P, Cagnoli L, Casanova S, Donini U, Pasquali S (1983) Focal glomerulosclerosis in patients with unilateral nephrectomy. Kidney Int 24:649-655

10. http://www.kidney.org/professionals/KDOQI/guidelines_ckd/ p4_class_g1.htm

11. Grubb A, Lofberg H (1985) Human gamma trace. Scand J Clin Lab Invest 45(177):7-13

12. Tenstad O, Roald AB, Grubb A, Aukland K (1996) Renal handling of radiolabeled human cystatin $\mathrm{C}$ in the rats. Scand $\mathrm{J}$ Clin Lab Invest 56:409-414

13. Fischbach M, Graff V, Terzic J, Bergere V, Oudet M, Hamel G (2002) Impact of age on reference values for serum concentration of cystatin C in children. Pediatr Nephrol 17:104-106

14. Filler G, Lepage N (2003) Should Schwartz formula for estimation of GFR be replaced by cystatin C formula. Pediatr Nephrol 18:981-985

15. Schwartz GJ, Munoz A, Schneider MF, Mak RH, Kaskel F, Warady BA, Furth SL (2009) New equations to estimate GFR in children with CKD. J Am Soc Nephrol 20:629-637

16. Perrone RD, Steinman TI, Beck GJ, Skibinski CI, Royal HD, Lawlor M, Hunsicker LG (1990) Utility of radioscopic filtration markers in chronic renal insufficiency: simultaneous comparison 
of 125I-iothalamate, 169Yb-DPTA, and inulin. The Modification of Diet in Renal Diseases Study. Am J Kidney Dis 16:224-235

17. SIOP WT 2001 Clinical Trial and Study Protocol, 2001

18. Schwartz GJ, Brion LP, Spitzer A (1987) The use of plasma creatinine concentration for estimating glomerular filtration rate in infants, children and adolescents. Pediatr Clin N Am 34:571-590

19. Hogg RJ, Portman RJ, Milliner D, Lemley KV, Eddy A, Ingelfinger J (2000) Evaluation and management of proteinuria and nephritic syndrome in children: recommendations from a pediatric nephrology panel established at the National Kidney Foundation conference on proteinuria, albuminuria, risk, assessment, detection, and elimination (PARADE). Pediatrics 105(6):1242-1249

20. Guignard JP, Santos F (2004) Laboratory investigations. In: Avner ED, Harmon WE, Niaudet P (eds) Pediatric nephrology. Lippincott Williams \& Wilkins, Philadelphia

21. http://www.kidney.org/professionals/KDOQI/guidelines_ckd/ Gif_File/kck_t63.gif

22. Paivansalo MJ, Kallioinen MJ, Merikanto JS, Jalovaara PK (1991) Hyperechoic "rings" in the periphery of renal medullary pyramids as a sign of renal disease. J Clin Ultrasound 19:283-287

23. National High Blood Pressure Education Program Working Group on High Blood Pressure in Children and Adolescents (2004) The Fourth Report on the Diagnosis, Evaluating, and Treatment of High Blood Pressure in Children and Adolescents. Pediatrics 114:555-576

24. Levitt GA, Yeomans E, Dicks Mircaux C, Breatnach F, Kingston J, Prichard J (1992) Renal size and function after cure of Wilms tumor. Br J Cancer 66:877-882

25. Srinivas M, Agarwala S, Padhy AK, Gupta AK, Bajpai M, Bhatnagar V, Gupta DK, Mitra DK (1998) Somatic growth and renal function after unilateral nephrectomy for Wilms' tumor. Pediatr Surg Int 14(3):185-188

26. Schell M, Cochat P, Hadj-Aissa A, Bouffet E, Dubourg L, BrunatMentigny M (1995) Renal function following unilateral nephrectomy for neuroblastoma and Wilms tumor. Pediatr Nephrol 9:579-582

27. Chevallier C, Hadj-Aissa A, Brunat-Mentigny M, Faraj G, Schell M, Cochat P (1997) Renal function after nephrectomy for Wilms' tumor. Arch Pediatr 7:639-644
28. http://www.kidney.org/professionals/KDOQI/guidelines_ckd/ p5 lab g4.htm

29. Seikaly MG, Browne R, Bajaj G, Arant BS Jr (1996) Limitation to body length/serum creatinine ratio as an estimate of glomerular filtration in children. Pediatr Nephrol 10:709-711

30. Donckerwolcke RM, Coppes MJ (2001) Adaptation of renal function after unilateral nephrectomy in children with renal tumors. Pediatr Nephrol 16:568-574

31. Mattman A, Eintracht S, Mock T, Schick G, Seccombe DW, Hurley RM, White CT (2006) Estimating pediatric glomerular filtration rates in the era of chronic kidney disease. J Am Soc Nephrol 17:486-487

32. Kazama JJ, Kutsuwada K, Ataka K, Maruyama H, Gejyo F (2002) Serum cystatin $\mathrm{C}$ reliably detects renal dysfunction in patients with various renal diseases. Nephron 91:13-20

33. Stefanowicz J, Kosiak M, Kosiak W, Korbus-Kosiak A, Sierota D, Owczuk R (2010) Cystatin C and parenchymal thickness/kidney length ratio in Wilms tumour survivors. Pediatr Blood Cancer $54: 41-46$

34. http://www.kidney.org/professionals/KDOQI/guidelines_ckd/ p4_class_g1.htm

35. http://www.kidney.org/professionals/KDOQI/guidelines_ckd/ p5 lab g5.htm

36. Di Tullio MT, Casale F, Indolfi P, Polito C, Giuliano M, Martini A, Cimmaruta E, Morgera C, Cioce F, Greco N (1996) Compensatory hypertrophy and progressive renal damage in children nephrectomized for Wilms tumor. Med Pediatr Oncol 26:325-328

37. Cioce F, Indolfi P, Di Tulio MT, Casale F, De Rosa E, Polito C (2001) Letter to the Editor: Kidney size and function after unilateral nephrectomy for Wilms tumor: a longitudinal study. Med Pediatr Oncol 37:485-486

38. Hernanz-Schulman M (1991) Hyperechoic renal medullary pyramids in infants and children. Radiology 181:9-11

39. Barrera M, Roy PL, Stevens M (1989) Long-term follow-up after unilateral nephrectomy and radiotherapy for Wilms' tumour. Pediatr Nephrol 3:430-432 